\title{
Comparing Resistant Microorganisms Isolated from Patients and Environment in an Intensive Care Unit
}

\author{
Quésia Souza Damaceno, Robert Iquiapaza, Adriana C. Oliveira \\ School of Nursing, Universidade Federal de Minas Gerais, Belo Horizonte, Brazil \\ Email: adrianacoliveira@gmail.com, rquiapaza@gmail.com, \\ qsdamasceno@gmail.com
}

Received 11 September 2013; revised 11 October 2013; accepted 18 October 2013

Copyright (C) 2014 by authors and Scientific Research Publishing Inc.

This work is licensed under the Creative Commons Attribution International License (CC BY). http://creativecommons.org/licenses/by/4.0/

\section{Open Access}

\begin{abstract}
Background: Recently, the probable involvement of surfaces from the hospital environment as a disseminating source of resistant bacteria has been highlighted. The aim of the study was to compare resistant microorganisms isolated from inanimate surfaces, equipments and patient blood culture samples in an Intensive Care Unit from Belo Horizonte, Brazil. Methods: A cross-sectional study was performed from July to October 2009. Data sources were microbiologic samples from environment and patient blood culture. Duplicate samples were obtained by swabs from up to seven different touch sites around two different patients in four different days. Jointly with the environmental samples, bacterial isolates from an adult ICU patients' routine blood cultures were obtained from hospital laboratory. The samples were identified, tested for sensitivity and compared by rep-PCR test to verify similarity. Results: Difference among the averages of Colony Forming Units was found within the environment samples $(p<0.004)$. In the environment were identified antibiotic resistant microorganisms such as Vancomycin resistant Enterococcus faecalis, imipenem and ciprofloxacin Pseudomonas aeruginosa and multidrug-resistant Acinetobacter baumannii. Similarities (60\% - 80\%) were established among environmental and blood culture samples. Conclusion: The environmental sampling showed different averages of contamination of the surfaces and equipment. The similarity among the bacterial isolates of patients' blood cultures and environmental samples reinforces the hypothesis of the horizontal transference of pathogens.
\end{abstract}

\section{Keywords}

Cross Infection; Bacterial; Drug Resistance; Intensive Care Units; Environment; Contamination 


\section{Introduction}

The surfaces near colonized patients, or those touched frequently by health professionals and by those who move within the area, can become contaminated by antibiotic resistant bacteria, especially methicillin resistant Staphylococcus aureus-MRSA [1] [2] and vancomycin resistant enterococcus-VRE [3].

Recently, the probable involvement of surfaces and equipment from the hospital environment as a disseminating source of pathogens, including resistant bacteria, has been highlighted [4]. There are no meaningful standards for permissible levels of microbial contamination of inanimate surfaces in hospital environment, but an increased microbial load on surfaces may imply the possibility of finding a pathogen [5].

The spread of pathogens in the hospital environment may be favored by some aspects such as the quantities of equipment and surfaces and patients status. One such example is the intensive care units (ICUs) with patients under intensive care [2] [3] [6].

Therefore, within this context, it is pertinent to question if there is in fact a relationship between bacterial isolates from patient's clinical samples, such as the routine blood culture, and the possible contamination of the inanimate surfaces, equipment and solutions of an ICU, considering the microorganisms of greater prevalence within the literature and of epidemiological importance within the institution of study (Acinetobacter baumannii, Staphylococcus aureus, Pseudomonas aeruginosa, Klebsiella pneumoniae and Enterococcus spp.).

The aim of this study was to compare resistant microorganisms isolated from inanimate surfaces, equipments and patient blood culture samples in an Intensive Care Unit (ICU) from Belo Horizonte, Brazil.

\section{Materials and Methods}

\subsection{Study Design}

This was a cross-sectional study of an adult ICU from a University hospital in Belo Horizonte, Brazil, from July to October 2009. Duplicate samples were obtained by swabs from up to seven different touch sites around two different patients in four different days. The surfaces sampled were from the command buttons of the cardiac function monitor, from the tracheal tube connected to the mechanical ventilator, the bed rail, the internal rims of the faucet, the top of the bedside table, the diaphragm of the stethoscope, and the upper borders of the sink, within a patient unit of an isolation unit or rooms. The sampling area for each surface was $1 \mathrm{~cm}^{2}$. The surfaces for sampling were defined according to those described in other studies as contaminated by epidemiological important bacteria [1]-[5] [7]-[11].

Jointly with the environmental samples, bacterial isolates from an adult ICU patients' routine blood cultures were obtained from hospital laboratory according to the unit protocol.

\subsection{Microbiological and Molecular Tests}

The samples from the ICU environment were distributed within culture mediums of Brain Heart Infusion (BHI), MacConkey, and Sabouraud Agar solutions and incubated at $37^{\circ} \mathrm{C}$ for 48 hours. The semiquantitative count of microbial growing was done for each medium. Colonies were enumerated and used to calculate the Colony Forming Units (CFU)/ml. Colonies with different morphologies were isolated. The isolates were submitted to Gram coloration as well as to biochemical and physiological tests (API identification Kits from BioMérieux, Lyon, Marcy-L'Etoile). After the identification of the API Kit, an antibiogram was performed with the bacterial isolates (Bauer-Kirby method) and with the more commonly used antimicrobials within the ICU-vancomycin, imipenem, ciprofloxacin, and ceftriaxone. In the case of Staphylococcus aureus and Enterococcus faecalis, the test of susceptibility to vancomycin was carried out by applying the technique of diluting the antimicrobial in Agar solution [12]. Staphylococcus aureus-ATCC 29213 was used for control of the test of susceptibility. The isolates with a resistance profile were selected for analysis using the repetitive extragenic palindromic sequence - Polymerase chain reaction (rep-PCR).

The total DNA was extracted. For the rep-PCR, the primers (GTG) 5 and Box $(0.3 \mu \mathrm{M})$ were used. To view the PCR results, the samples were run through a 2.0\% agarose gel (Invitrogen-Carlsbad, CA) for two hours at 70 voltz, colored by ethidium bromide and photographed in ultra-violet light. For this, a 1 Kb Plus DNA Ladder, ready-to-use, 75 - 20.00 bp (Fermentas-Burlington, Ontario, Canada) molecular marker was used. 


\subsection{Data Analyses}

The profiles generated by the rep-PCR were analyzed using the BioNumerics version 6.0 program (Applied Maths, St. Martens-Latem, Belgium). The comparison between the profile pairs of the BOX-PCR and the (GTG) 5 were calculated using the Pearson correlation coefficient. The analyses for grouping similar values were carried out using the Unweighted pair-group (UPGMA) algorithm. The data were analyzed by the Kruskal-Wallis test within the SPSS version 13.0 statistics program. This study was approved by the Ethics Committee, number 113/09.

\section{Results}

The Kruskal-Wallis test identified an important difference among the averages $(P<0.004)$ of Colony Forming Units-CFU/ml found within the samples obtained by swabs of the cardiac function monitor, the mechanical ventilator, the stethoscope, the bed rail, the faucet, the bedside table, and the sink (Table 1).

The identification of bacterial isolates by API kit (ranged from 77.5\% to 99.3\%) and antibiogram performed by Bauer-Kirby method showed epidemiological important microorganisms within the studied ICU, the following were found in the patient isolation units: imipenem, ciprofloxacin, and ceftriaxone resistant Acinetobacter baumannii; ciprofloxacin resistant Staphylococcus aureus; and vancomycin and ciprofloxacin resistant Enterococcus faecalis (Figure 1).

From the blood cultures of patients, were isolated four Gram negative bacilli, resistant to ceftriaxone and/or ciprofloxacin, tree Staphylococcus epidermidis resistant to ciprofloxacin, and four were classified as intermediary concerning their pattern of response toward ceftriaxone and ciprofloxacin.

The similarity among environmental and patient's blood culture samples amplified by the GTG (5) and BOX primers ranged from $60 \%$ to $80 \%$ (Confidence Interval-IC: $85 \%$ ).

\section{Discussion}

The environmental sampling by swabs showed different averages of contamination of the surfaces and equipment that may be related to: the proximity of the equipment or surface to the patient, the frequency with which professionals and people who visit the sector touch the objects, decontamination, type of material, among other factors [4] [13].

During concurrent cleaning, the environment decontamination of the studied adult ICU is performed according to the routine protocol, including the daily decontamination of the surfaces with $70 \%$ ethyl alcohol. During terminal cleaning, after patient discharge, transference, or death, the entire unit, including the floors and walls, are washed, followed by the application of sodium hypochlorite $(10.000 \mathrm{ppm})$ for non-metallic surfaces and floors.

The detection of the resistant bacteria on surfaces and equipment is most likely related to the possibility of recontamination, several hours after the hygienization of the environment, or even due to the possible of some microorganisms persist on surfaces after cleaning, in addition to the high frequency of manipulation and touch, as they refer to locations that demand repetitive re-evaluation of the parameters of the patient in his/her clinical condition [9] [14].

The presence of multidrug-resistant Acinetobacter baumannii on room surfaces, even after four rounds of routine terminal cleaning and disinfection of rooms newly vacated by patient carrying this microorganism, was found by Manian et al. [15]. The terminal cleaning and disinfection of rooms included "wiping of visibly soiled

Table 1. Average of Colony Forming Units/ml from equipments and surfaces samples from an Intensive Care Unit—Belo Horizonte, 2010.

\begin{tabular}{cccc}
\hline Equipments & Colony Forming Units & Surfaces & Colony Forming Units \\
Cardiac Monitor & $92.5(9.25 \times 10 \mathrm{CFU} / \mathrm{ml})$ & Bed rail & $305\left(3.05 \times 10^{2} \mathrm{CFU} / \mathrm{ml}\right)$ \\
Mechanical Ventilator & $313.25\left(3.13 \times 10^{2} \mathrm{CFU} / \mathrm{ml}\right)$ & Faucet & $2098.3\left(2.09 \times 10^{3} \mathrm{CFU} / \mathrm{ml}\right)$ \\
Stethoscopes & $740\left(7.4 \times 10^{2} \mathrm{CFU} / \mathrm{ml}\right)$ & Bedside table & $80(8.0 \times 10 \mathrm{CFU} / \mathrm{ml})$ \\
\hline
\end{tabular}




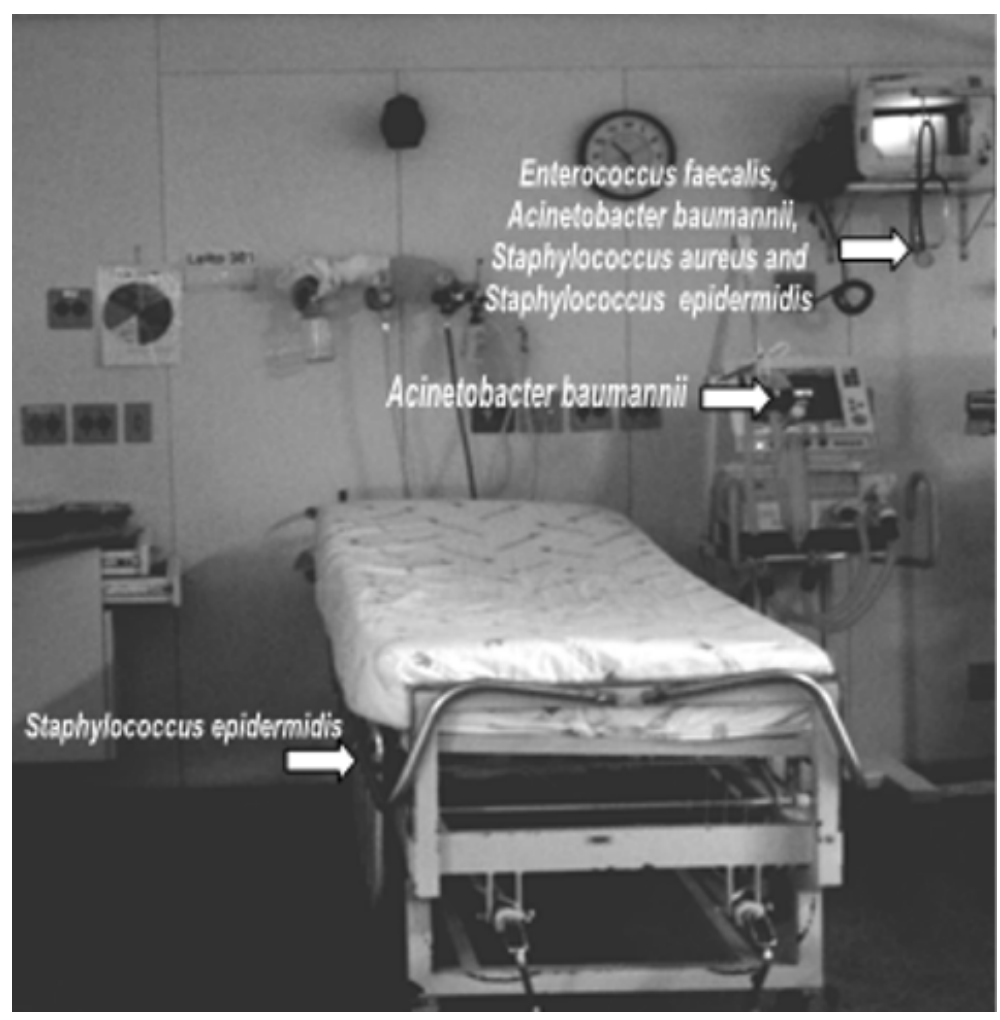

Figure 1. Distribution of resistant bacteria on surfaces and equipment in an isolated room of an ICU-Belo Horizonte, 2010.

surfaces with a quaternary ammonium compound followed by disinfection with $0.525 \%$ sodium hypochlorite solution (1:10 dilution)" [15].

The contamination of surfaces with resistant microorganisms may increase its spread among patients and hospital environment. Hayden et al. [3] found that 52\% of healthcare workers had the hands or gloves contaminated with VRE after touching the environment in a room occupied by a patient carrying this microorganism [3].

In studies on the environment's participation in the dissemination of pathogens, the contamination of surfaces near the patient or those touched many times by health professional, and fomites could be observed. On surfaces of the bed, Acinetobacter baumannii, VRE, and MRSA were the most common, with the last being the most frequent. In addition, these were found on door-knobs, chairs, toilet seats, tables, computer keyboards, and diaphragms of stethoscopes [1] [2] [6] [9] [16] [17]. On the faucets, Pseudomonas aeruginosa was the most common, especially in humid locations [8] [18] [19].

In this study according to the grouping of profiles generated by the rep-PCR, with primers GTG [5] and BOX of the bacterial isolates, no significant diversity among the samples from the ICU environment and patient blood cultures in the sector could be observed, in accordance with the similarly percentage of $70 \%$ proposed for species level [20].

\section{Conclusions}

In conclusion, it was possible to verify similarity among some isolates of resistant bacteria recovered from equipment and inanimate surfaces and patient blood culture. Such a similarity among the bacterial isolates of patients' blood cultures and environmental samples reinforces the hypothesis of the horizontal transference of pathogens.

The contamination of the equipment and surfaces by resistant bacteria reinforces the need to pay closer attention to the disinfectants used due to the possibility of favoring the dissemination of different pathogens. Most notably is the importance of the reinforcement of the control, reduction and prevention measures applied against the dissemination of the resistant microorganisms. These aspects are not analyzed in the present study, but they 
are of great relevance within this context.

\section{Acknowledgements}

The authors thank Professor Dr Jacques R. Nicoli for the permission to use the laboratory of Microorganisms Ecology and Physiology to perform the tests and, the Central Laboratory of Clinical Hospital of UFMG for the permission of routine blood cultures from adult ICU patients and the Fundação de Amparo à Pesquisa de Minas Gerais for the support [APQ-00328-08].

\section{References}

[1] Hardy, K.J., Oppenheim, B.A., Gossain, S., Gao, F. and Hawkey, P.M. (2006) A Study of the Relationship between Environmental Contamination with Methicillin-Resistant Staphylococcus Aureus (MRSA) and Patients’ Acquisition of MRSA. Infection Control and Hospital Epidemiology, 27, 127-132. http://dx.doi.org/10.1086/500622

[2] Sexton, T., Clark, P., O’Neill, E., Dillane, T. and Humphreys, H. (2006) Environmental Reservoirs of Methicillin-Resistant Staphylococcus aureus in Isolation Rooms: Correlation with Patient Isolates and Implications for Hospital Hygiene. Journal of Hospital Infection, 62, 187-194. http://dx.doi.org/10.1016/j.jhin.2005.07.017

[3] Hayden, M.K., Blom, D.W., Lyle, E.A., Moore, C.G. and Weistein, R.A. (2008) Risk of Hand or Glove Contamination after Contact with Vancomycin-Resistant Enterococcus or the Colonized Patients' Environment. Infection Control and Hospital Epidemiology, 29, 149-154. http://dx.doi.org/10.1086/524331

[4] Sehulster, L.M., Chinn, R.Y.W., Arduino, M.J., Carpenter, J., Donlan, R. and Ashford, D. (2003) Guidelines for Environmental Infection Control in Health-Care Facilities. Recommendations from Centers for Disease Control and Prevention (CDC) and the Healthcare Infection Control Practices Advisory Committee (HICPAC). Chicago: American Society for Healthcare Engineering/American Hospital Association. http://www.cdc.gov/hicpac/pdf/guidelines/eic_in_HCF_03.pdf. Accessed 13 January 2012.

[5] Dancer, S.J. (2004) How Do We Assess Hospital Cleaning? A Proposal for Microbiological Standards for Surfaces Hygiene in Hospital. Journal of Hospital Infection, 56, 10-15. http://dx.doi.org/10.1016/j.jhin.2003.09.017

[6] Huang, S.S., Datta, R. and Plat, R. (2006) Risk of Acquiring Antibiotic-Resistant Bacteria from Prior Room Occupants. Archives of Internal Medicine, 166, 1945-1951. http://dx.doi.org/10.1001/archinte.166.18.1945

[7] Bures, S., Fishbain, J.T., Uyehara, C.F.T., Parker, J.M. and Berg, B.W. (2000) Computer Keyboards and Faucet Handles as Reservoirs of Nosocomial Pathogens in Intensive Care Unit. American Journal of Infect Infection Control, 28, 465-470. http://dx.doi.org/10.1067/mic.2000.107267

[8] Corona-Nakamura, A.L., Miranda-Novales, M.G. and Leãnos-Miranda, B. (2001) Epidemiologic Study of Pseudomonas aeruginosa in Critical Patients and Reservoirs. Archives of Medical Research, 32, 238-242. http://dx.doi.org/10.1016/S0188-4409(01)00267-3

[9] Drees, M., Snydman, D.R., Schmid, C.H., Barefoot, L., Hansjosten, K., Vue, P.M., Cronin, M., Nasraway, S.A. and Golan, Y. (2008) Prior Environmental Contamination Increases the Risk of Acquisition of Vancomycin-Resistant Enterococci. Clinical Infectious Diseases, 46, 678-685. http://dx.doi.org/10.1086/527394

[10] Lemmen, S.W., Häfner, H., Zolldann, D., Stanzel, S. and Lüttichen, R. (2004) Distribuition of Multi-Resistant GramNegative versus Gram-Positive Bacteria in the Hospital Inanimate Environment. Journal of Hospital Infection, 56, 191-197. http://dx.doi.org/10.1016/j.jhin.2003.12.004

[11] Rohr, U., Kaminski, A., Wilhelm, M., Jurzik, L., Gatermann, S. and Muhr, G. (2009) Colonization of Patients and Contamination of the Patients' Environment by MRSA under Conditions of Single-Room Isolation. International Journal of Hygiene and Environmental Health, 212, 209-15. http://dx.doi.org/10.1016/j.ijheh.2008.05.003

[12] Clinical and Laboratory Standards Institute (2009) Performance Standards for Antimicrobial Disk Susceptibility Tests; Approved Standard. 10th Edition, CLSI Document M02-A10. Clinical and Laboratory Standards Institute (CLSI), Wayne.

[13] Carling, P.C., Parry, M.F., Bruno-Murta, L.A. and Dick, B. (2010) Improving Environmental Hygiene in 27 Intensive Care Units to Decrease Multidrug-Resistant Bacterial Transmission. Critical Care Medicine, 38, 1054-1059. http://dx.doi.org/10.1097/CCM.0b013e3181cdf705

[14] Hardy, K.J., Gossain, S., Henderson, N., Drugan, C., Oppenheim, B.A., Gao, F. and Hawkey, P.M. (2007) Rapid Recontamination with MRSA of the Environment of an Intensive Care Unit after Decontamination with Hydrogen Peroxide Vapour. Journal of Hospital Infection, 66, 360-368. http://dx.doi.org/10.1016/j.jhin.2007.05.009

[15] Manian, F.A., Griesenauer, S., Senkel, D., Setzer, J.M., Doll, S.A., Perry, A.M. and Wiechens, M. (2011) Isolation of Acinetobacter baumannii Complex and Methicillin-Resistant Staphylococcus aureus from Hospital Rooms Following 
Terminal Cleaning and Disinfection: Can We Do Better? Infection Control and Hospital Epidemiology, 32, 667-672.

[16] El Shafie, S.S., Alishaq, M. and Garcia, M.L. (2004) Investigation of an Outbreak of Multidrug-Resistant Acinetobacter baumannii in Trauma Intensive Care Unit. Journal of Hospital Infection, 56, 101-105. http://dx.doi.org/10.1016/j.jhin.2003.09.024

[17] Rutalla, A.W., White, M.S., Gergen, M.F. and Weber, D.J. (2006) Bacterial Contamination of Keyboards: Efficacy and Functional Impact of Disinfectants. Infection Control and Hospital Epidemiology, 27, 372-377. http://dx.doi.org/10.1086/503340

[18] Petignat, C., Francioli, P., Nahimana, N., Wenger, A., Bille, J., Schaller, M.D., Revelly, J.P., Zanetti, G. and Blanc, D.S. (2006) Exogenous Source of Pseudomonas aeruginosa in an Intensive Care Unit Patients: Implementation of Infection Control and Follow-Up with Molecular Typing. Infection Control and Hospital Epidemiology, 27, 953-957. http://dx.doi.org/10.1086/506409

[19] Rogues, A.M., Boulestreau, H., Lashe’ras, A., Boyer, A., Gruson, D., Merle, C., Castaing, Y., Bébear, C.M. and Gachie, J.P. (2007) Contribution of Tap Water to Patient Colonisation with Pseudomonas aeruginosa in a Medical Intensive Care Unit. Journal of Hospital Infection, 67, 72-78. http://dx.doi.org/10.1016/j.jhin.2007.06.019

[20] Wayne, L.G., Brender, D.J., Colewll, R.R., Grimont, P.A.D., Kandler, O., Krichevsky, L.H., Moore, L.H., Moore, E.C., Murray, R.G.E., Stachebrandt, E., Starr, M.P. and Truper, H.G. (1987) Report of the Ad Hoc Committee on Reconciliation of Approaches to Bacterial Systematics. International Journal of Systematic Bacteriology, 37, 463-464. http://dx.doi.org/10.1099/00207713-37-4-463 